\title{
A DISJUNCT DISTRIBUTION FOR A NEW SPECIES OF ORCHESELLIDES (COLLEMBOLA, ENTOMOBRYIDAE, ORCHESELLINAE) ${ }^{1}$
}

\author{
Rafael Jordana ${ }^{2}$ and Enrique Baquero ${ }^{2}$
}

ABSTRACT: A new species of Orchesellides is described from material collected in the Valsaín forest (Segovia, Spain), and conserved in the collection of the National Museum of Natural Sciences (MNCN), CSIC, Madrid. The genus was known only from the eastern Palaearctic, Oriental, and Indo-Pacific (Hawaii) regions. This is the first reference for the genus from the western Palaearctic region, creating an interesting disjunct distribution. The value of the morphological characteristics for the identification of the species is discussed.

KEY WORDS: Orchesellides, disjunct distribution, western Palaearctic region, Iberian Peninsula, Spain

Through the courtesy of Carolina Martín, we had the opportunity to study the collection of the family Entomobryidae at the National Museum of Natural Sciences (MNCN), CSIC (Madrid, Spain). Among the material studied we found five slides with 24 specimens of a species of Orchesellides from Valsaín (Segovia, Spain) (sample M40). These specimens had been labeled Entomobrya or Orchesella. The species previously described for the genus are O. boraoi Bonet, 1930 (Pakistan), O. kabulensis Yosii, 1966 (Afghanistan), O. lineatus Mari Mutt, 1983 (Korea), O. poli Yosii, 1966 (Afghanistan), O. sinensis (Denis, 1929) Yosii, 1966 (China, Japan and Hawaii), O. szeptyckii Mari Mutt, 1983 (Korea), O. viridis Mari Mutt, 1983 (Korea) and O. crassa (Imms, 1912) (Himalaya). The present paper extends the distribution of the genus to the western Palaearctic region.

\section{KEY TO THE SPECIES OF ORCHESELLIDES}

1 Antennal segment 5 with bilobed apical papilla ..................................... 2

- Antennal segment 5 without apical papilla ............................................... 6

2 Color green ..................................................................................... $\mathrm{O}$. viridis

- Color blue-violet

3 Tenaculum with two setae .................................................... O. szeptyckii

- Tenaculum with one seta .................................................................... 4

4 Pin seta on antennal segment 5 pointed ................................................... 5

- $\quad$ Pin seta on antennal segment 5 bifurcate ...................................... O. boraoi

5 Non annulated dens/mucro ratio $=4$. Coxae without pigment

O. kabulensis

\footnotetext{
${ }^{1}$ Received on March 8, 2005. Accepted on July 24, 2005.

${ }^{2}$ Department of Zoology and Ecology, University of Navarra, P. O. Box 177, 31080 Pamplona, Navarra, Spain. E-mails: rjordana@unav.es (corresponding author), ebaquero@unav.es, respectively.
} 
- Non annulated dens/mucro ratio $=6$. Coxae with pigment O. poli

6 Head without trichobothrium O. sinensis

- Head with trichobothrium 7

7 Pin seta on antennal segment 5 trifurcate, unguiculous outer tooth distal, above the fifty percent from its base O. lineatus

- Pin seta on antennal segment 5 bifurcate, unguiculous outer tooth at about the forty percent from its base O. carolinae n. sp.

\section{Orchesellides carolinae Jordana and Baquero, NEW SPECIES}

(Figs. 1-2)

Description. Body length to $1.7 \mathrm{~mm}$ (minimum $1.1 \mathrm{~mm}$, mean $1.4 \mathrm{~mm}, \mathrm{SD}$ $0.16 \mathrm{~mm}, \mathrm{n}=24$ ). General measurements in Table 1. Background color yellowish, with blue-violet patches principally over abdominal segment I-III, but with pale patches on other areas (Fig. 1A). Antenna with five segments by sub-segmentation of antennal segment I. Apex of antennal segment $\mathrm{V}$ without papilla and with bifurcate pin seta (Fig. 1B). Antennal segment IV sensory organ with two small rods in a small groove with the typical accessory sensillae (Fig. 1C). Antennal segment I and II (Fig. 1D) not clearly separated in juveniles. Eyes 8+8, $\mathrm{G}$ and $\mathrm{H}$ smaller than the others. Prelabral setae smooth and labral papillae with hooked projections (Fig. E). Unguis morphology as in figure 1F: inner margin with paired teeth at about the middle and two distal unpaired teeth; lateral teeth more basal than paired teeth and well developed, dorsal tooth at about basal third of unguis. Trochanteral organ with about 16 small setae. Tenaculum with four teeth in each ramus and one seta on the corpus. Manubrial plate with one internal and four external setae (Fig. 1G). Mucro bidentate with basal seta (Fig. 1H). Body with typical entomobryid type setae: type 1, type 2 and type 5 (Christiansen 1958) (Fig. 1I). Head macrochaetotaxy as in figure 2A. Body macrochaetotaxy and distribution of trichobothria as in figures 2B-C. Head and thoracic segments II and III with macrochaetae type 1 (different sizes) and type 5. Abdominal segments I-V with macrochaetae type 2 (different sizes) and type 5. Posterior half of abdominal segment IV with numerous long sensillae not previously reported for members of the genus.

Type Material. Holotype. Female, SPAIN, Valsaín Forest, Segovia, Pinus sylvestris, code MNCN-Valsaín-M40, 30.X.1971, Margarita Acón and José Carlos Simón leg. Paratypes, 23 specimens with same data. Type material deposited in National Museum of Natural Sciences (MNCN), CSIC, Madrid.

Etymology. The species is dedicated to Carolina Martín (MNCN), who kindly provided the studied material. 


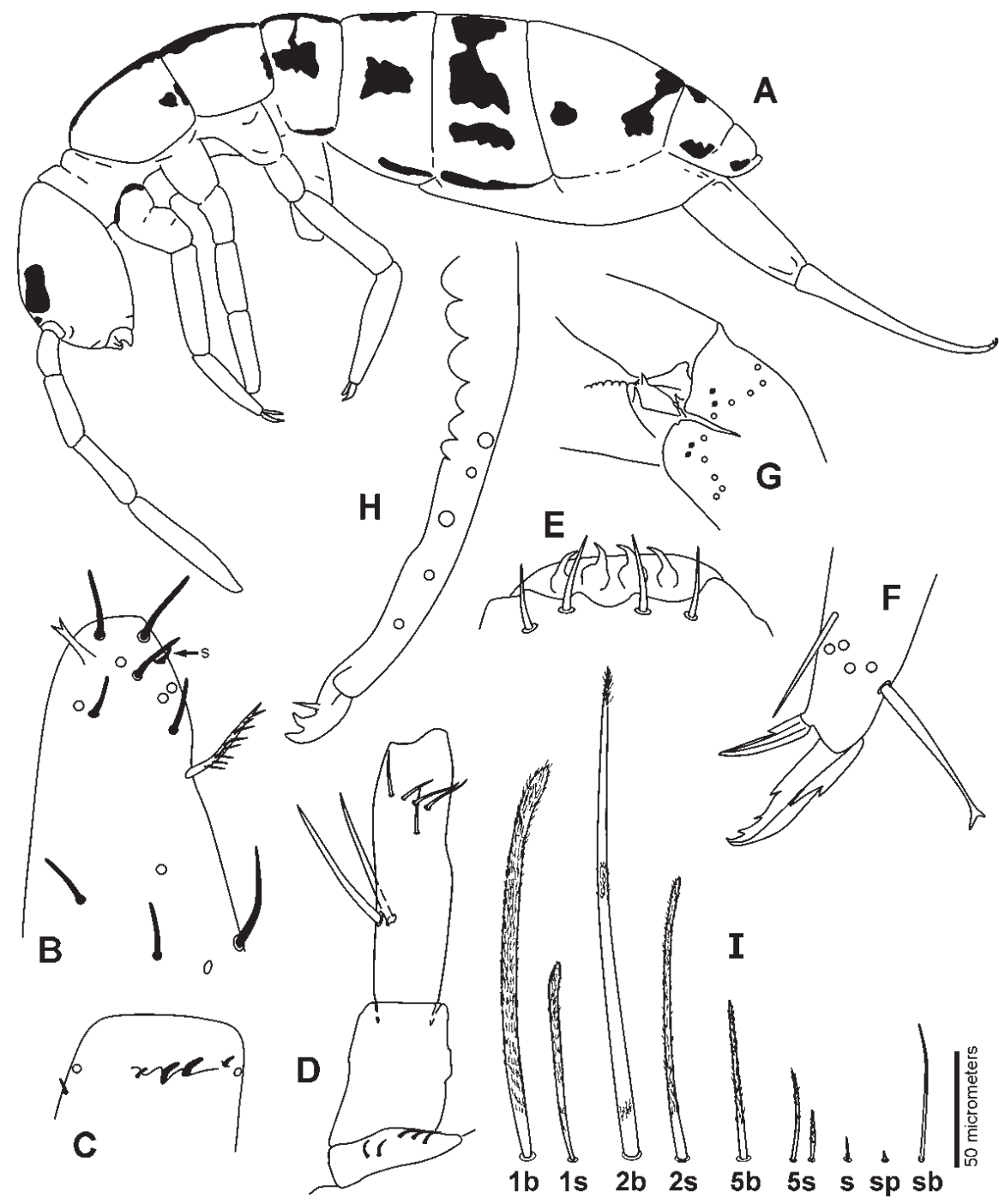

Fig. 1. Orchesellides carolinae n. sp. A. Pattern color, lateral habitus. B. Tip of antennal segment five. C. Sensory organ of antennal segment four. D. Antennal segments 1-3. E. Labral papillae and first row of labral setae. F. Unguis and unguiculus. G. Manubrial plate. H. Distal part of dens. I. Types of setae (following to Christiansen, 1958): 1b, type $1 \mathrm{big}$, drawing from thoracic segment II; 1s, type 2 small, drawing from thoracic segment II; $2 \mathrm{~b}$, type 2 big, from abdominal segment IV; $2 \mathrm{~s}$, type 2 small; 5 b, type 5 big; 5 s, type 5 small; s, sensilla; sp, spine; sb, sensilla big -only on abdominal segment IV-. Bar scale only for sensillae. 


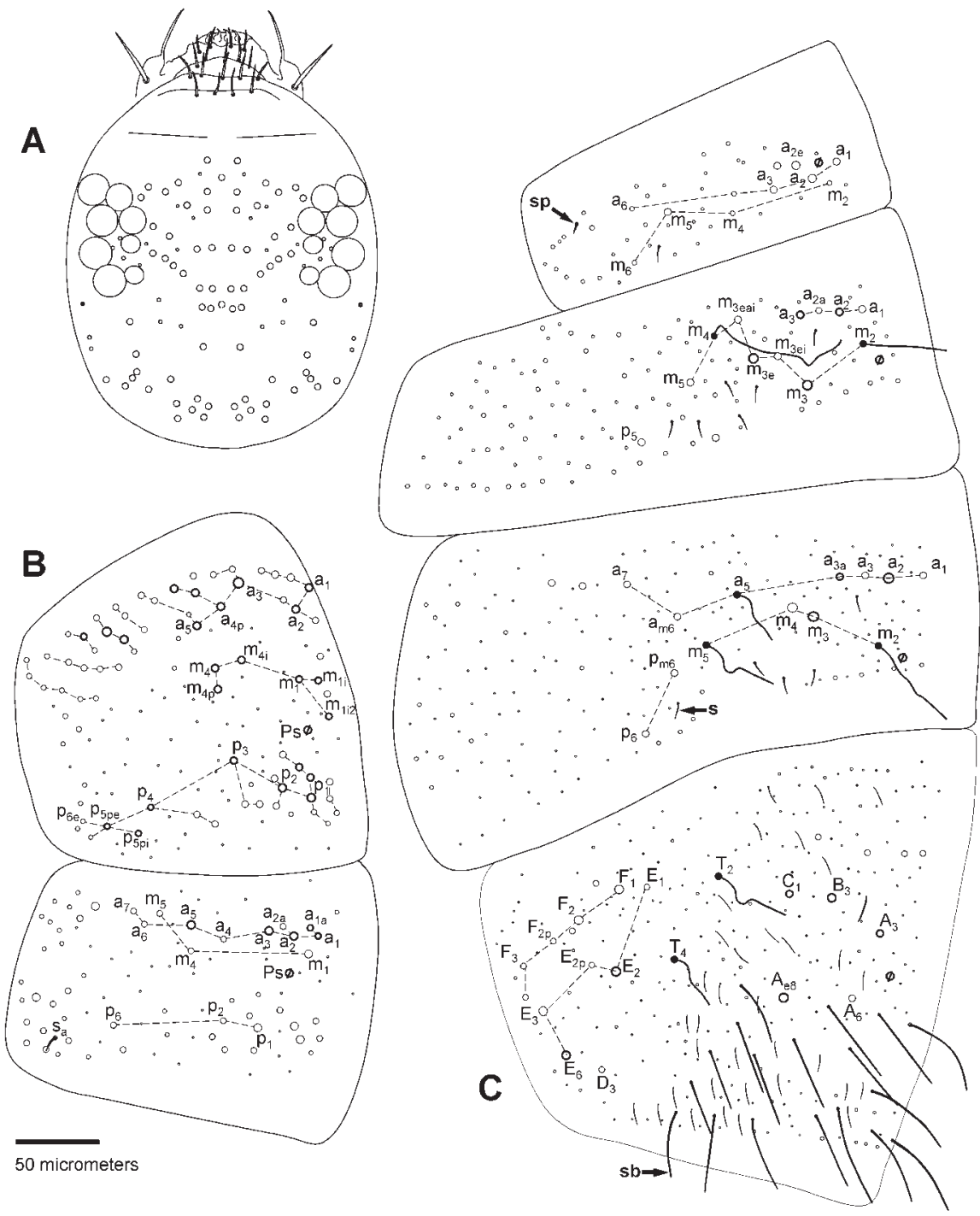

Fig. 2. Orchesellides carolinae n. sp. chaetotaxy. A. Head. B. Thoracic segments II and III. C. Abdominal segments I-IV. The circles with heavy outline are macrochaetae. 


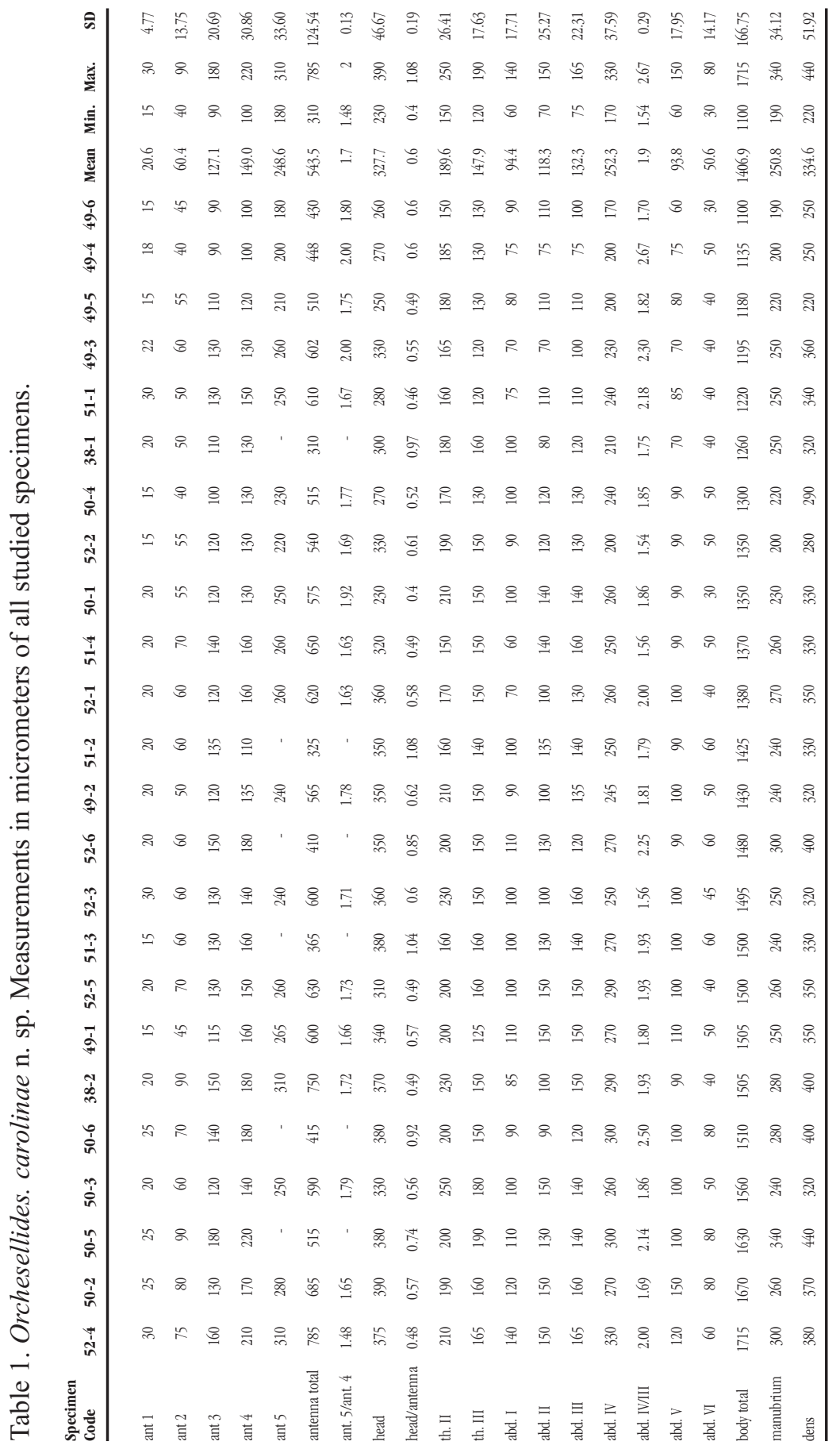




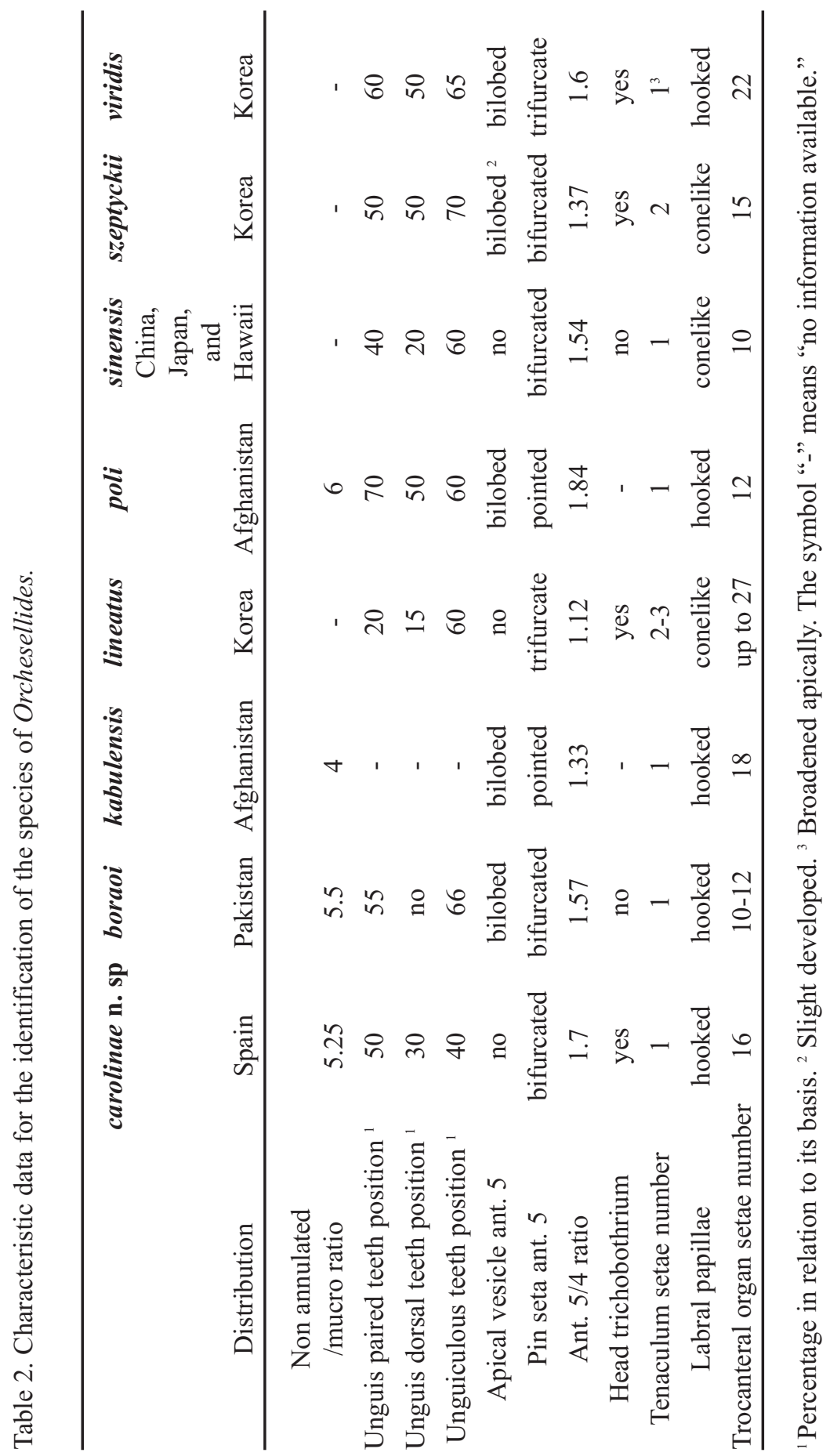




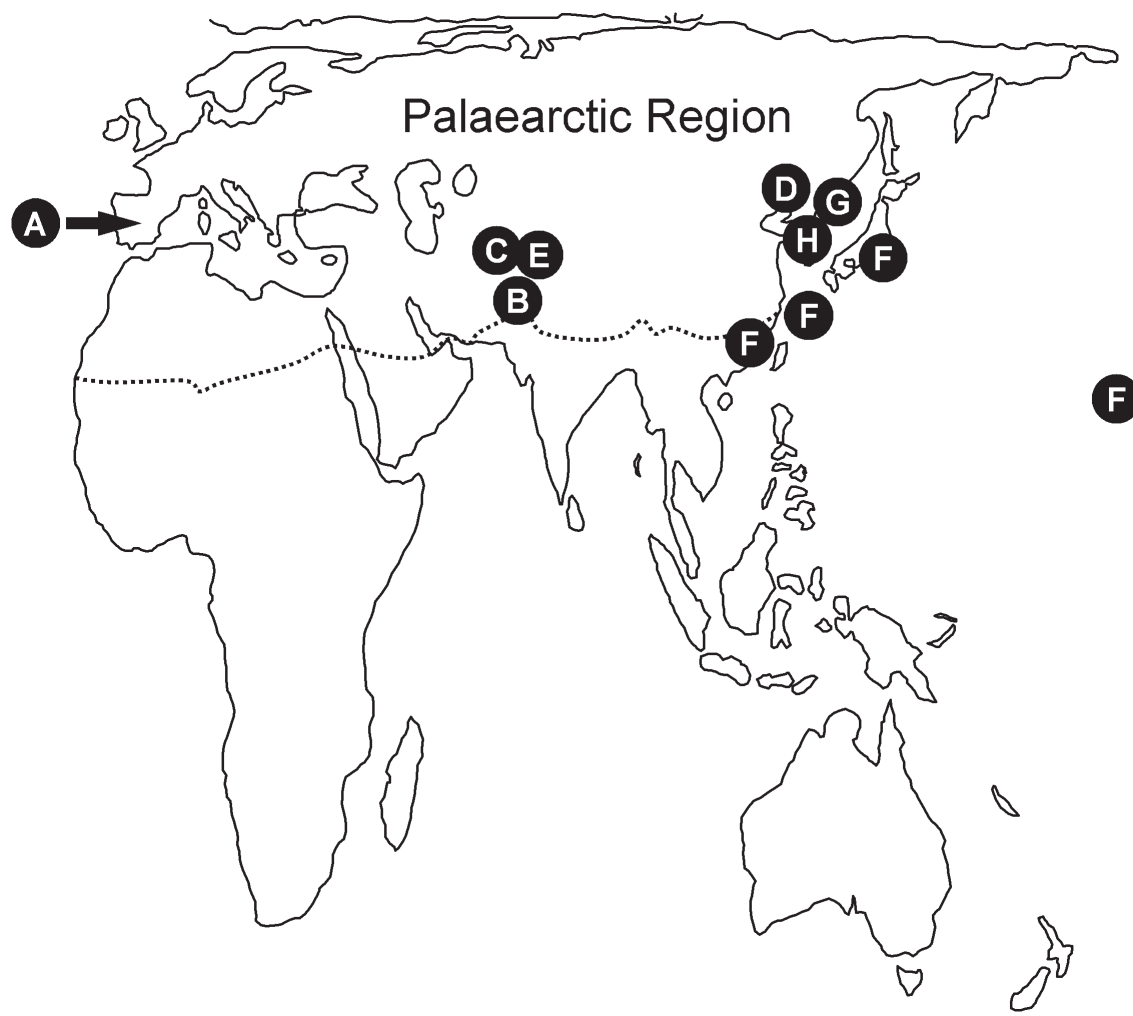

Fig. 3. Distribution of the described species of Orchesellides. A. O. carolinae n. sp. Valsaín, Segovia, Spain. B. O. boraoi Miram-Shah, Pakistan. C. O. kabulensis Kabul, Afghanistan. D. O. lineatus Hanghe-namdo, N Korea. E. O. poli Mt. Noshaq, Afghanistan. F. O. sinensis Fukien, China; Kioto and Okinawa, Japan; Hawaii. G. O. szeptyckii Kangvôn-do, N Korea. H. O. viridis Janggang-do, N Korea.

\section{DISCUSSION}

There are few characteristics to distinguish the species of Orchesellides. Most useful characters, with exception of coloration, are included in the key and in Table 2, and have been obtained from the original descriptions by Bonet (1930), Mari Mutt $(1983,1986)$ and Yosii (1966). In our opinion morphologic characters (e.g., chaetotaxy, foot complex, etc.) are more reliable than color pattern in reflecting species specific differences because it is often difficult to find and study fresh material in which the color has not been altered by the preserving agent. The position of the outer tooth of the unguiculus is a very useful and easily observable characteristic of $O$. carolinae n. sp., and only $O$. lineatus, $O$. sinensis and the new species lack the apical vesicle on antennal segment 5 . The setae 
number on the tenaculum was used in the key although Mari Mutt (1983) reports to vary from 1-3 setae between conspecific individuals of $O$. lineatus and $O$. szeptyckii. The chaetotaxy of the new species is very similar to the one described by Szeptycki (1979) for Orchesellides sp., really O. viridis (by personal communication from Szeptycki to Mari Mutt, 1983). The presence of long sensillae on the abdominal tergite IV is very characteristic of $O$. carolinae n. sp.

Orchesellides crassa (Imms, 1912) was described as Entomobrya crassa probably by an inaccurate observation of the antennal segments (Bonet, 1930). This species has not been considered in the present study because the original description is insufficient for diagnosis and we were unable to examine the holotype.

The genus Orchesellides is recognized by the absence of scales and the presence of a subdivided first antennal segment. The subdivision of the first antennal segment is hard to see or may be absent in juvenile specimens, resulting in misidentifications as unrecognizable species of Entomobrya or juvenile Orchesella. It is remarkable to discover a species of Orchesellides in the western Palaearctic since the other species of the genus are found far away, east of the Caspian Sea (Fig. 3).

\section{ACKNOWLEDGEMENTS}

We are grateful to Dr. Soto-Adames (Department of Biology, University of Vermont) for his useful suggestions during the preparation of the manuscript, to Dr. Simon (Department of Biology (Zoology), University Autonomous of Madrid) for his help to the localization of the sampling period, and Dr. Carolina Martín (National Museum of Natural Sciences, Madrid) for the loan of the material.

\section{LITERATURE CITED}

Bonet, F. 1930. Sur quelques Collemboles de l'Inde. Eos. 6: 249-273.

Christiansen, K. 1958. The Nearctic members of the genus Entomobrya (Collembola). Bulletin of the Museum of Comparative Zoology 118(7): 1-545. 24 pl.

Mari Mutt, J. A. 1983. Three new Species of Orchesellides from North Korea (Collembola: Entomobryidae: Orchesellinae). International Journal of Entomology 25(4): 297-309.

Mari Mutt, J. A. 1986. Contribución al conocimiento de tres especies de Orchesellinae descritas por F. Bonet y redescripción de Orchesellides sinensis (Denis). Eos. 61: 189-198.

Szeptycki, A. 1979. Chaetotaxy of the Entomobryidae and its phylogenetical significance. Morphosystematic studies on Collembola. IV. Polska. Akademia Nauk., Zaklad Zoologii Systematycznej I. Doswiadczalnej. Krakow, 218 pp.

Yosii, R. 1966. On some Collembola of Afghanistan, India and Ceylon, collected by the Kupheexpedition, 1960. Results Kyoto University Scientific Expedition to the Karakoram \& Hindukush 8: 333-405. 